there is still a wastage rate. This rate depends on how complex and arduous the subsequent training is, and a high wastage rate may show simply that the selection procedure was no more than a preliminary sieving out of the obviously unsuitable. Thus it might be regarded as desirable that a certain proportion of medical students should fail their examinations, though this would be hard on the individuals concerned, because it would indicate that the initial selection was not so exclusive as to eliminate the unusual candidate or the late developer. There are dangers in measuring the success of selection from examination results because results tend to alter with the average capabilities of those selected. If the average fluctuates, the standard of the examination tends to follow suit; there can be no absolute standard. This danger is less if large numbers of candidates are interviewed by different selection panels.

On the whole it is far easier to test the various physical skills than it is to test the more elusive qualities of mind and temperament, the qualities that enable a man to perform some feat of courage and intelligence when the occasion demands. Recently Captain J. G. Perry, of the U.S. Air Force, discussed some of the criteria used in selecting men for space missions. ${ }^{2}$ Two facts should be noted. First, the fifteen candidates he describes were career officers in the U.S. Air Force and U.S. Navy and had already been highly selected on entry to the services and during training. Secondly, selection has been successful in that set-backs in the American space programme have all been technical and have not been caused by failure of the astronauts, though of course it will never be known how those not selected would have performed.

Several features of general interest emerge from the study. One is that all the men interviewed were enthusiasts, and the comment is made that they would have been successful in any profession if chance had not led them to be fliers. Another is that all the men had experienced emergencies in which their lives were threatened and they had been able to deal with the situation in a cool and detached manner, overriding the classical flight-fight response ; all had experienced anxiety but never during the actual emergency. This kind of mental detachment is important because it enables the individual to react rationally to the threat and to take appropriate action. Fear reduces the efficiency of adaptive behaviour, but on the other hand it actually improves performance in simple conditioned responses; hence the importance of training.

In selecting men for space missions there have been conscious attempts to match the man to the job according to his capacity to withstand certain stresses, such as isolation, sensory deprivation, immobility, and overload of information, but, as Perry says, "How can simulation give rise to the feelings of expectation, realization, accomplishment and fulfilment which ... will exist in every instance at the moment of the mission ?" All astronauts, not surprisingly, have reported these feelings as dominant during the mission, and presumably there were physiological concomitants to these feelings every bit as powerful as those to anxiety and other negative states.

Each candidate was assessed by two psychiatrists, a clinical psychologist, and by the other candidates themselves. Assessments were made independently and a number of ranking orders established. There were considerable differences in

\footnotetext{
See "Aircrew Performance," Section 8, in Textbook of Aviation
Physiology, ed. J. A. Gillies, 1965. Oxford.

${ }^{2}$ Perry, J. G., f. Amer. med. Ass., 1965, 194, 841.
}

the order in which each member of the psychiatric team placed the candidates, but most interestingly there was better agreement among the fifteen candidates on their own pecking order. The composite orders of all the evaluators and all the candidates also differed, but there was fair agreement at the lower end, three candidates being put in the lowest five in each list. This result confirms a widely held impression that it is easier to select out or eliminate than it is to make a positive choice. At the top end the disagreement was great. Only one of the first five candidates chosen by the psychiatric team appeared in the candidates' first five, and the candidates' top man was only twelfth on the psychiatrists' list. Perry says that this disagreement should not detract from the validity of psychiatric impressions, since psychiatrists used psychiatric criteria, whereas the candidates used test-pilot criteria. But, as Perry says, "Who, at this point, is to say that their selection is less valid than the one which is psychiatrically determined ?"

It would seem reasonable perhaps to place more weight on psychiatric assessment in eliminating candidates, because a psychiatrist is more familiar with pathological states, latent or overt. But in drawing up a ranking order of successful candidates the candidates themselves may be in a better position to establish their own pecking order. One does after all judge a man by the company he keeps, and much can be learnt about a medical student from the opinions of his fellow students. It is probably impracticable to introduce the house-party selection procedure for medical students, but it might eliminate some of the more disastrous mistakes in selection.

\section{Maternal Deaths}

One of the most instructive pieces of self-criticism which the medical profession undergoes is the Confidential Inquiry into Maternal Deaths in England and Wales. To the three previous reports ${ }^{1-3}$ a fourth has recently been added. ${ }^{4}$ The inquiry provides an analysis of all the deaths which were due to or associated with pregnancy or childbirth. One of the chief features of the investigation is the assessment by the Ministry of Health's consultant advisers on obstetrics of "avoidable factors" in the circumstances of the deaths.

During 1961-3 there were 2,550,252 births and 816 maternal deaths directly due to pregnancy. It is worth noting that in the first three-year period (1952-4) of the inquiry the maternal death rate was more than double that in the present series. Confidential reports on the deaths due to pregnancy or childbirth and to associated causes showed that the four main causes in order of frequency were abortion, pulmonary embolism, toxaemia, and haemorrhage.

There was evidence that $77(55.4 \%)$ of the 139 cases of abortion were illegally procured. Of these women 21 were married, 25 were unmarried, and for 31 the marital status was not given. There were seven other cases in which the probability that abortion had been procured was very great but proof was absent. Of the five deaths following therapeutic abortion, one was due to carcinoma of the breast, one to shock, one to septicaemia, and two to pulmonary embolism.

Thirty-six of the 129 deaths from pulmonary embolism occurred during pregnancy, compared with only four in the 1952-4 series. No explanation can be given for this rise. There was, however, a fall in the number after vaginal 
delivery from 104 in 1952-4 to 66 in 1961-3. Pulmonary embolism also caused the death of 27 women after caesarean section. An additional and more detailed inquiry is now being made whenever a maternal death is ascribed to this cause.

"Avoidable factors" were found in 51 of the 104 deaths from toxaemia. The main ones were considered to be lack of cooperation from the patient, inadequate antenatal care, confusion of responsibility, and wrong booking for domiciliary or maternity-home confinement. About half of the 96 deaths from haemorrhage were "avoidable," and it would seem from examples given in the report that some doctors failed to make proper and full use of the maternity flying squads.

Cardiac disease complicating pregnancy accounted for 68 deaths, with an avoidable factor in at least 18. "Labour was difficult and further hazards appeared when the doctor working single-handed [in a general-practitioner maternity home] attempted a forceps delivery under chloroform anaesthesia." This was in a woman with known cardiac disease having a first pregnancy late in life. In another case the doctor wrote, "Why should all heart cases be delivered in hospital ?" Hospital doctors are not blameless either. Two patients were sent home after valvotomy without arrangements being made for their antenatal care.

The caesarean-section rate went up from $2.4 \%$ in 1957 to $3.2 \%$ in 1963 , while the estimated number of deaths per 1,000 caesarean sections fell from 3.3 in 1957 to 1.5 in 1963 . Avoidable factors in 32 cases included booking of unsuitable cases for maternity homes or home confinements, consultant advice sought too late, inadequate use of flying squad, and decision to operate and actual operation the responsibility of a junior medical officer without supervision.

Inhaled stomach contents accounted for 12 of the 14 deaths with avoidable factors among the 28 due to anaesthesia. Failure to intubate the trachea or compress the cricoid seemed to be the commonest fault. Pudendal nerve block is a good technique-but not for difficult forceps deliveries. In two such cases death resulted from inhalation of vomit because general anaesthesia had to be induced in a hurry.

The 38 deaths from rupture of the uterus illustrate the need to observe the generally accepted contraindications before booking a woman for confinement in her home or a maternity home. Twenty-seven deaths were considered to be due to amniotic-fluid embolism, and the report proposes criteria for an absolute and for a presumptive diagnosis of the condition.

Altogether avoidable factors were present in 262 of the 692 deaths analysed $(37.9 \%)$. This compares favourably with the $43.1 \%$ in $1952-4$ but is still too high. Most of these factors arose in the antenatal period, and many deaths could have been avoided by booking high-risk cases for hospital care, seeking consultant advice, or calling on the flying squad. Neglect by the mother herself to make suitable arrangements for her confinement or to follow the advice of the doctor or midwife accounted for a substantial number (44 solely and 33 partially responsible). In some of these cases perhaps greater persuasion by doctors or midwives would have prevented the death.

The very safety of childbearing paradoxically tempts some women and doctors to take a needless risk. But the high-

1 Brit. med. 7., 1957, 2, 280.

- Ibid., 1960, 2, 123.

- Ibid., 1963, 1, 903.

- Ibid., 1963, 1, 903. Reports on Public Health and Medical Subjects No. 115. Report on Confidential Inquiries into Maternal Deaths in England and Wales 1961-3. 1966. H.M.S.O. risk groups are now well recognized, and usually there is timely warning that the woman has changed from a low-risk to a high-risk category and that expert help is required. Though childbearing continues to be increasingly safe, further improvement could readily come from ensuring that all high-risk cases are confined in hospital.

\section{Farewell at Hammersmith}

On 27 July Professor Sir John McMichael, F.R.S., conducted his last staff round and clinicopathological conference at the Postgraduate Medical School at Hammersmith. The normal Wednesday morning gathering was packed by many of the doctors who had held appointments in the department of medicine while Sir John was director. McMichael succeeded Sir Francis Fraser in 1946, having been acting director during the war years. His own work at Hammersmith, first on liver disease and later on special techniques for the investigation of cardiopulmonary disease, has secured his place in the ranks of leading clinical scientists ; but his great achievement was to maintain at Hammersmith an atmosphere of enthusiasm, constructive criticism, and cooperation, so that the best young research workers were attracted by the high standards of those already there. This chain reaction led to the recognition of the Hammersmith as the finest school for postgraduate training in the Commonwealth, where few, if any, of the university clinical departments are now without Hammersmith men.

In October Sir John takes up his new post as director of the British Postgraduate Medical Federation. The qualities that he brings to this appointment can only accelerate the improvement of postgraduate training in Britain.

\section{Growing Points}

Complaints about the alarming pace of medical progress today are commonplace, and the gibe that the textbook or the proceedings of a conference are out of date before they are published is frequently heard. Understandably, therefore, the busy and harassed doctor may decide that it is impossible to catch up with some subjects-usually those, such as genetics, in which progress has been particularly rapid. Yet often the subjects have both intrinsic interest and potential clinical importance. To try to remedy this the B.M.F. is publishing a series of occasional articles on the "growing points" of medicine. The first of these, by Dr. Martin Hartog on hormones and the endocrine system, appeared earlier this year, ${ }^{1}$ and at p. 345 of this week's issue we print the first of three articles by Dr. G. R. Fraser on genetics. Future articles are planned to deal with viruses, autoimmune conditions, and renal disease.

$$
1 \text { Hartog, M., Brit. med. F., 1966, 1, } 225 .
$$

On 23 July Sir John Peel was elected President of the Royal College of Obstetricians and Gynaecologists in succession to Sir Hector MacLennan. 